
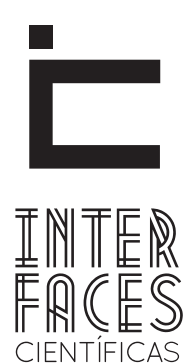

EDUCAÇÃO

ISSN IMPRESSO 2316-333X

E-ISSN 2316-3828

DOI-10.17564/2316-3828.2017v5n3p113-122

\title{
UM ESTUDO SOBRE ALGUNS DOS ENSINAMENTOS REALIZADOS POR HUGO DE SÃO VITOR E SÃO BOAVENTURA DE BAGNOREGIO
}

\section{A STUDY ON SOME OF THE LESSONS ARE PERFORMED BY HUGH OF SAINT VICTOR AND SAINT BONAVENTURE OF BAGNOREGIO UN ESTUDIO SOBRE ALGUNAS DE LAS LECCIONES REALIZADAS POR HUGO DE SAN VÍCTOR Y SAN BUENAVENTURA}

Conceição Solange Bution Perin ${ }^{1}$

Claudinei Magno Magre Mendes ${ }^{3}$
Terezinha Oliveira²

\section{RESUMO}

A pesquisa visa algumas questões sobre educação e ensino tratadas por dois autores clássicos da Idade Média: Hugo de São Vitor (1096-1141) e São Boaventura de Bagnoregio (1217-1274). 0 objetivo principal do estudo é entender como esses pensadores evidenciaram o ensino aos homens das suas épocas históricas e a importância do conhecimento para inserirem-se na sociedade à qual faziam parte. Ao estudarmos a História da Educação compreendemos a necessidade da reflexão sobre os valores que independem do período histórico para serem considerados essenciais para a formação humana. Compreendemos que o passado e o presente estão relacionados e que, sem esse entendimento, não conseguimos compreender as prioridades educacionais que possibilitaram a re/organização social em diferentes momentos históricos. Nesse sentido, para proceder à análise, adotamos o método que prioriza o tempo, a história de longa duração e a possibilidade de diferentes hipóteses, criadas por historiadores que debatem com outras ciências sociais.

\section{PALAVRAS-CHAVE:}

Ensino. Hugo de São Vitor. Boaventura de Bagnoregio 


\section{ABSTRACT}

The research aims at some questions about education and teaching treated by two classic authors of the Middle Ages: Hugh of Saint Victor (1096-1141) and Saint Bonaventure of Bagnoregio (1217-1274). The main objective of the study is to understand how these thinkers showed the teaching to the men of their historical epochs and the importance of the knowledge to insert themselves in the society to which they were part. As we study the History of Education we understand the need for reflection on values that, independent of the historical period, are considered essential for human formation. We understand that the past and the present are related and that, without this understanding, we fail to understand the educational priorities that have enabled social re-organization at different historical moments. In this sense, in order to proceed with the analysis, we adopt the method that prioritizes time, the long history and the possibility of different hypotheses, created by historians who debate with other social sciences.

\section{KEYWORDS}

\author{
Teaching. Hugo of St. Victor. Bonaventure \\ of Bagnoregio
}

\section{RESUMEN}

La investigación apunta a algunas preguntas sobre la educación y la enseñanza abordadas por dos autores clásicos de la Edad Media: Hugo de San Víctor (10961141) y San Buenaventura de Bagnoregio (12171274). El objetivo principal del estudio es entender cómo estos pensadores demostraron la enseñanza a los hombres de su época histórica y la importancia del conocimiento para insertarse en la sociedad a la que formaban parte. Mientras se estudiaba la Historia de la Educación se percibió la necesidad de reflexionar sobre los valores que son independientes del período histórico para que sean consideradas esenciales al desarrollo humano. Entendemos que el pasado y el presente están relacionados y que sin este entendimiento, no se puede entender las prioridades educativas que hicieron posible la re/organización social en diferentes momentos históricos. En este sentido, para hacer el análisis, adoptamos el método que da prioridad a tiempo, la historia de largo plazo y la posibilidad de diferentes hipótesis, creados por los historiadores que discuten con otras ciencias sociales.

\section{PALABRAS-CLAVE}

Educación. Hugo de San Víctor. San Buenaventura. 


\section{INTRODUÇÃO}

Este estudo analisa o ensino na Idade Média, especificamente nos séculos XII e XIII, e tem o objetivo de relacionar o pensamento pedagógico de Hugo de São Vitor (1096-1141) e São Boaventura de Bagnoregio (1221-1274), presente nas várias obras desses autores, nas quais eles expõem sobre a importância da meditação e da contemplação para a formação do homem. Para tanto, a pesquisa tem como base teórico-metodológica a análise histórica pela totalidade, fundamentada em autores que tratam da História Social, como Marc Bloch (2001), e que contribuem com o nosso foco de estudo, ou seja, o nosso propósito não é investigar somente como alguma questão aconteceu no passado, mas sim como podemos fazer uso desse conhecimento do passado, visando compreender algumas questões do presente. Bloch nos recorda que "[...] a ignorância do passado não se limita a prejudicar a compreensão do presente; compromete, no presente, a própria ação" (BLOCH, 2001, p. 63).

Algumas considerações acerca do pensamento desses mestres medievais e suas contribuições para a História da Educação e para o ensino nos levam a entender a ética na conduta humana para adquirir a sabedoria, bem como, a disciplina, o método e a organização como forma de alcançar o conhecimento.

\section{DESENVOLVIMENTO}

Pensar a educação e o ensino, historicamente, requer entender que homens do passado priorizavam as boas ações humanas, entendendo que o bem comum deveria estar presente em toda e qualquer atitude social. O individual, para São Vitor e Boaventura, corresponde ao esquecimento dos valores que perpassam o uso do intelecto, pois, a inteligência, segundo Boaventura, foi dada por Deus a fim de que os homens desfrutem do conhecimento para o uso do bem coletivo.

Desse modo, compreendemos que a educação perpassa o conhecimento formal, escolar e abrange a formação humana, no sentido de desenvolver/reforçar bons hábitos, costumes e valores. São Vitor, por exemplo, prioriza o uso da reflexão por meio dos estudos, pois ele entende que quanto mais se conhece e se instrui, mais o homem se disciplina, entende as regras estabelecidas e, consequentemente, se compreende como homem e também as necessidades dos valores humanos para a organização da sociedade.

Para tanto, ele explana sobre a importância da aproximação do trabalho humano com a natureza, ou seja, para o autor, o homem ao aproximar-se da natureza por meio do trabalho, se aproxima de Deus, materializando a sua Inteligência na ação realizada em São Vitor o trabalho humano é uma imitação da natureza “[...] que as formas presentes na 'forma do bem perfeito', que é a Mente divina (Sapientia), materializam-se nas formas da natureza" (MARCHIONNI, 2001, p. 31).

São Vitor apresenta questões que permanecem e se fortalecem em séculos posteriores ao seu, com discussões que norteiam a fé e a razão como distintas, mas essenciais para a formação do homem, revelando que 0 uso da razão favorece o fortalecimento da fé, apresentando por meio do conhecimento, a existência de Deus. Nesse contexto, São Vitor considera como primordial ensinar o homem a aprender. Segundo o autor, é preciso didática e disciplina para a concentração e o aprendizado. Estudar significa ter um tempo de dedicação para a reflexão, para a contemplação e um ambiente que possa favorecer o ensinar e $o$ aprender.

Segundo analisa Boaventura a inteligência é tão completa que, ao ser utilizada com base nos ensinamentos divinos, permite ao homem descobrir os diferentes seres que compõem o mundo, bem como a finalidade de cada um: pelo raciocínio, pela crença, pela contemplação.

A via do raciocínio, da crença e da contemplação são elementos de conhecimentos que relacionam os debates realizados pelos dois autores quando fazem a comparação do discurso de quem profere com a interpretação do ouvinte. Para eles, a responsabilidade da fala é muito importante, porque a inteligência, dada ao homem por Deus, favorece aos seres humanos condições de revelarem o seu pensamento por meio da oralidade e do tom da voz emitida. Para explicar 
melhor, Boaventura, por exemplo, consegue construir uma compreensão dos sentidos relacioando-os com a intencionalidade pessoal.

Segundo ele, cada sentido é acompanhado do prazer de "[...] buscar o objeto sensível que the é conveniente" (BOAVENTURA, 1983, p. 212), isto é, os cinco sentidos (visão, audição, tato, olfato, paladar) se fartam daquilo que lhes é conveniente: o olho não se farta de ver; o ouvido de ouvir; a boca de comer; o nariz de cheirar; as mãos de tocar. Quem dá o controle aos sentidos é o cérebro, regido pela inteligência que, por sua vez, é determinada pelo conhecimento "Eis como a divina sabedoria se encerra, embora de forma oculta, no conhecimento sensível e quão admirável é a contemplação dos cinco sentidos espirituais, segundo a conformidade que têm com os sentidos corporais" (BOAVENTURA, 1983, p. 212).

Se o homem conhece pelos sentidos, confirma a existência do seu conhecimento pela fé, pela autoridade da mente ou pelo que Boaventura chama 'o calor da sabedoria'. Assim, todo e qualquer conhecimento é devidamente compreendido se for conforme a ordenação do Senhor, de acordo com seus ensinamentos. Os sentidos desempenham, então, a função de conhecer. Para Boaventura, como perfeitas criações, os sentidos são o meio pelo qual o homem conhece para depois crer. Eles são 'portas' de entrada do conhecimento: na alma este se realiza na íntegra, pela fé.

O homem que é um "pequeno mundo", tem cinco sentidos que são como as portas, por meio das quais o conhecimento das realidades sensíveis entra em sua alma. Com efeito, pela vista entram os corpos celestes e luminosos e os corpos coloridos. Pelo tato entram os corpos sólidos e terrestres. Pelos outros três sentidos entram os corpos intermédios. Assim, pelo gosto entram os corpos líquidos; pelo ouvido, os aeriformes; pelo olfato, os vaporáveis (os quais participam da natureza da água, do ar e do fogo, como se pode ver no perfume que se exala dos aromas). Em resumo, os corpos simples e os corpos compostos entram em nossa alma por meio dos sentidos. (BOAVENTURA, 1983, p. 175).

A apreciação de Boaventura sobre os sentidos faz parte dos caminhos que ele concebe para o conheci- mento humano e das ideias que ele desenvolve a respeito de como essa criação perfeita que integra o corpo e a alma é possível. Para ele, os sentidos não favorecem apenas o conhecer do mundo sensível, mas também o conhecer do mundo abstrato. Cita, como exemplos, os números, a grandeza, o movimento, a figura e o repouso.

Nessa explicação, ele envereda por todas as suas implicações, por todos os detalhes, levando seus ouvintes a esclarecerem as dúvidas e buscarem a interpretação pela via divina.

O abstrato, ou, como ele denomina também, as coisas sensíveis que são objetos comuns dos sentidos, é entendido por meio da alma. O homem analisa o objeto e o vê, porém, a dimensão, o tamanho e/ou a espessura são imaginados e não concretizados pela porta dos sentidos. É a alma que leva a uma reflexão por meio do intelecto e ao entendimento do abstrato.

Pelo sentido, porém, não percebemos apenas as coisas sensíveis que são objetos próprio de certos sentidos, tais como a luz, o som, o odor, o sabor e as quatro qualidades primárias que o tato aprende. Pelo contrário, percebemos também as coisas sensíveis que são o objeto comum a muitos sentidos, tais como o número, a grandeza, a figura, o repouso, o movimento. Descobrimos igualmente que <<tudo o que se move é movido por outrem > > e que certos seres - os animais, por exemplo - têm em si mesmos a causa de seu movimento e se repouso. Daí segue-se que, quando nós percebemos por meio dos sentidos o movimento dos corpos, somos induzidos ao conhecimento das substâncias espirituais que os movem, assim como o efeito nos conduz ao conhecimento de sua causa. (BOAVENTURA, 1983, p. 175)

Os sentidos, então, para Boaventura, revelam ao homem que aquilo que não se vê, embora exista, pode ser conhecido por ele. Sobre o movimento, por exemplo, o autor comenta: uma coisa se move pelo fato de outra coisa fazê-la mover, seja o vento ou a própria mente. De acordo com Boaventura, as coisas materiais não entram pelos sentidos, mas suas imagens e semelhanças é que são captadas e transmitidas aos sentidos externos, que, na sequência, revelam a sua existência, quando analisadas pelo intelecto.

A prova da importância do intelecto e do fato de que ele foi dado aos homens por Deus para conhecer 
tem como objetivo explicar para os homens a importância de serem bons. Para voltar ao Criador, é preciso se eximir do pecado e seguir os ordenamentos de Deus, sem se deixar cair nas tentações, já que, muitas vezes, o corpo se trai e convence a mente.

A ligação realizada por Boaventura, entre os sentidos e os interesses humanos, que acabam regendo a vida inidivudual e o coletivo é, sem duvida, um ensinamento que estabelece na formação humana o uso do conhecimento como o principal orientador para a vida em sociedade.

\begin{abstract}
Se, porém, considerarmos o exercício dos sentidos, intuiremos aí a norma da vida. Porquanto cada um dos sentidos se exercita sobre seu próprio objeto, evita o que lhe é nocivo e não toma o objeto alheio. - De modo semelhante vive ordenadamente o sentido do coração, quando se exerce naquilo para o qual foi destinado, que é lutar contra a negligência; quando evita o que lhe é nocivo, luta contra concupiscência; e quando não toma o objeto alheio, luta contra a soberba. Pois toda a desordem provém da negligência, da concuspiscência ou da soberba. E vive ordenadamente aquele que vive prudente, temperado e submissamente, de maneira a evitar a negligência no agir, a concuspiscência no apetecer e a soberba no sobressair. (BOAVENTURA, 1983, p. 212).
\end{abstract}

Logo, o agir pela via do conhecimento, para o autor, possibilita um entendimento sobre as consequências que podem ocorrer pela ação humana. 0 homem, para esses autores e mediante a submissão da Sagrada Escritura, tem a responsabilidade de conduzir suas vidas de modo ordenado, reto e sem prejudicar o outro.

Desse modo, Boaventura assim como São Vitor, estabelecem o ensino como algo imprescindível para o desenvolvimento da inteligência e, consequentemente, do conhecimento. A leitura, por exemplo, pode ser considerada por eles como início do saber. Deve ter sempre alguém que ensina a ler e, é por meio da leitura que o homem começa a aprender. Conforme São Vitor, a leitura é o primeiro degrau para a Sapiência. "A leitura informativa, portanto, deve ser seguida pela reflexão meditativa, na qual alcança-se o discernimento crítico" (HUGO DE SÃO VITOR, 2001, p. 35).

Contemplar por meio da meditação corresponde a entender o significado das coisas que estão no cotidiano e as que estão além da nossa visualização. É acreditar na existência de Deus pela abstração. Aprender corresponde a aprofundar o conhecimento pela via da ciência, relacionar a importância de cada aprendizado com o que está exposto no dia a dia e que, muitas vezes, é ignorado ou mal compreendido pela falta de conhecimento científico.

Leitura e moral, de acordo com São Vitor, estão coadunadas com o exercício da leitura, pois, ler leva a prática (ação), entendendo que, quem lê, normalmente, medita sobre a leitura e faz uma reflexão do conteúdo que está lendo. A tradução de letras, palavras, frases, até a formação do texto corresponde a um exercício do cérebro que provoca o uso expressivo da concentração. Dessa forma, o esforço intelectual possibilita o pensar antes do agir, compreendendo que o uso da concentração de forma habitual resulta no hábito de reflexão antes da ação, fazendo com que o seu agir demonstre a sua moralidade.

A moral está relacionada com os ensinamentos divinos e é seguindo esses ensinamentos que o homem consegue discernir o bem e o mal. Portanto, o estudo por meio da leitura exige regras: “[...] primeiro, saber o que se deve ler; segundo, em que ordem se deve ler, ou seja, o que ler antes, o que depois; terceiro, como se deve ler" (HUGO DE SÃO VITOR, 2001, p. 45). A leitura, segundo São Vitor, requer meditação, silêncio e muita concentração. Logo, o ensinar e o aprender não são sinônimos de algo que se faz com naturalidade, mas sim com esforço e dedicação.

Boaventura vai além dessas questões apresentadas por São Vitor, tendo em vista que, para ele, o ensinar é uma responsabilidade de poucos. Ele deixa claro, por meio de suas afirmações, que a compreensão das ciências só é possível se estiver pautada nos ensinamentos divinos. Logo, o aprendizado estabelece um contato direto de Deus com os homens num processo de ensino.

Quem ensina deve ensinar como rezar, como aprender os ensinamentos do Criador, já que se estes não forem muito bem trabalhados e se não forem realizados por uma pessoa experiente e com muita sabedoria, os iniciantes podem não adquirir a capacidade 
de discernimento entre o bem e o mal. Ou, ainda, se forem orientados por alguém que não tenha o conhecimento reflexivo dos Ensinamentos Sagrados, agem sem pensar na humanidade. Esse alguém, segundo Boaventura, não é um líder ou um mestre, pois é próprio daquele que lidera e ensina pensar primeiro no próximo e depois em sua individualidade.

Para este autor, conhecimento é sinônimo de contribuir para o bem comum. Segundo ele, Deus criou o homem com a inteligência para ser desenvolvida de forma que trouxesse a ordem dos sentimentos, evitando usar os cinco sentidos para, como ele afirma: a soberba, a ambição e a negligência. Esses sentimentos geram desordem social, conflitos de relacionamentos e, consequentemente, são sentimentos de individualidade e não de bem estar social.

A preocupação desses autores com o conhecimento e com o pensar coletivo, nos favorece entender que o ensino deve ser realizado por alguém que consegue compreender a totalidade, que analisa a história como ensinamento para o presente e que nos possibilita enxergarmos, hoje, a nossa realidade dentro de um contexto com falta da ordem de sentimentos que geram o pensar comum.

Como dito anteriormente, Boaventura explica que os homens necessitam do aprendizado por meio da ciência, pois ele compreende que a prática social anseia por um conhecimento mais específico e observador da natureza. Porém, para esse esclarecimento, ele discorre detalhadamente e por vários meios de justificativa que, ao aprender a ciência, o homem está aprendendo a conhecer melhor a Deus. Boaventura considera Deus como centro de toda ciência. Não obstante, suas justificativas, sempre pautadas nas Sagradas Escrituras, conflitam com os ensinamentos pautados na teoria aristotélica, que entendia a razão como principal direcionamento de compreensão para todas as coisas.

Para São Vitor, nem todos os homens nascem com essa possibilidade de aprender, haja vista que há muitas pessoas que a própria natureza deixou tão desprovida de capacidades, que têm dificuldade para entender até as coisas mais fáceis (HUGO DE SÃO VITOR, 2001, p. 43). Com isso, São Vitor afirma que a sociedade não tem inteligência homogênea, as pessoas têm capacidades de desenvolver o intelecto de formas diferentes e, dentre aquelas desprovidas de capacidades, se destacam dois exemplos: aqueles que mesmo sem grandes capacidades têm vontade de conseguir estudar e mudar as suas limitações de aprendizado; aqueles que não têm vontade nem de aprender as mínimas coisas. Para o autor, estes últimos são do grupo que se distancia da presença de Deus.

São Vitor explica aos estudantes, a quem dirige seu método de ensino, que a história faz parte do aprendizado e que ela é uma das etapas principais para os passos seguintes do conhecimento. Sem dúvida é mister, no estudo, que você aprenda, antes de tudo, a história e a verdade dos fatos, retomando do começo ao fim (SÃO VITOR, 2001, p. 235). Segundo ele, é a partir do passado que é possível entender: 1) o que foi feito; 2) quando foi feito; 3) onde foi feito; 4) por quais pessoas foi feito (SÃO VITOR, 2001, p. 236).

0 autor vê na história a maneira de esclarecimento dos fatos que aconteceram no passado e que ainda podem apresentar resquícios no presente, por isso, ele afirma que o estudo não pode ser superficial. Dessa forma, ele diz: Não queira desprezar estes detalhes. Aquele que despreza as coisas mínimas aos poucos definha. Se você tivesse desdenhado de aprender como primeira coisa o alfabeto, agora não teria o nome nem entre os estudiosos da gramática (SÃO VITOR, 2001, p. 237).

Nesse sentido, São Vítor se utiliza da história para explicar que o verdadeiro conhecimento é realizado por meio de vários fatores que se relacionam e que, por muitas vezes, muitos deles são rejeitados sem nenhuma importância, porém, os pequenos detalhes conseguem dar um sentido àquilo que pensamos saber, mas não compreendemos sem a via do conhecimento.

Como nas virtudes, também nas ciências existem alguns degraus. Você dirá: "Encontro nas histórias muitas coisas que parecem não ter utilidade alguma, por que deveria ocupar-me de coisas desse tipo?" Você diz bem. Todavia, há muitas coisas nas Escrituras que, tomadas separadamente, parecem não ter nada a ser buscado, mas, se você as comparar com outras às quais estão ligadas, e começar a examiná-las em conjunto, verá que são igualmente necessárias e pro- 
cedentes. Algumas coisas devem ser conhecidas em si mesmas, outras ainda que não pareçam merecer a nossa aplicação, todavia de maneira alguma devem ser preteridas negligentemente, porque sem elas não podem ser conhecidas exaustivamente aquelas outras. Aprenda tudo, e verá depois que nada é supérfluo. 0 saber limitado não é alegre. (SÃO VITOR, 2001, p. 239).

Afirmado por São Vitor de que o conhecimento científico é essencial e que existem alguns degraus a serem alcançados, vamos entender algumas dessas etapas, também, pela explicação de Boaventura. 0 autor estabelece uma ordem para se criar a relação entre o conhecimento e Criador. Apresenta três caminhos: o do vestígio, o da imagem e o da semelhança.

[...] pode-se coligir que a criação do mundo é como que um livro, no qual resplandesce, representa-se e lê-se a Trindade criadora em três graus de expressão, a saber: como vestígio, como imagem e como semelhança. 0 vestígio encontra-se em todas as criaturas; a imagem, só nos intelectuais; isso é, nos espíritos racionais; a semelhança, só nos deiformes. Por elas o entendimento está destinado a subir gradualmente, como que por degraus, até o Princípio soberano, que é Deus. (BOAVENTURA, 1983, p.51).

Segundo Boaventura, para desenvolver os estágios da inteligência e interpretar os ensinamentos de Deus, o homem precisa sair do estado de vestígio, que corresponde à primeira relação de dependência com o Criador; ou seja, sair do estágio de inocência, que propicia comportamentos e ações sem reflexão. Essa fase, pela qual todos passam, só se altera quando se fizer uso do intelecto.

O estágio seguinte, denominado imagem, é o da inteligência, da mediação entre a fase inicial (vestígio) e a final (semelhança). 0 desenvolvimento do intelecto leva o indivíduo a uma aproximação com Deus, pois o conhecimento de seus ensinamentos e a interpretação de suas palavras favorece outro comportamento, diferente do inicial. Esse estágio, para Boaventura, é o do espírito racional, o intermediário.

Por último, ele caracteriza o da semelhança: a fase da fé obtida por meio do conhecimento da ciência no estágio anterior. Se o homem conseguir conhe- cer Deus pelo espírito racional, ele terá mais fé para conhecer Deus e tudo o que foi criado por Ele. Desse modo, o indivíduo não se conforma com qualquer explicação. Exige coerência e explicações lógicas para a sua credibilidade, ou seja, por meio de seu intelecto já pode compreender o empírico e o abstrato, sem a dúvida de crer no que não se vê.

Para esta tríplice visão, o homem recebeu três olhos, como diz Hugo de São Vitor, a saber, o da carne, para ver o mundo e as coisas que nele se encontram; o da razão, para ver a alma e o que nela se encontra; o da contemplação, para ver Deus e o que nele se encontra. Assim, pelo olho da carne, o homem vê as coisas que estão fora dele; pelo da razão as que estão dentro dele; pelo da contemplação, as que estão acima dele. Mas o olho da contemplação não chega à perfeição de seu ato a não ser pela glória, que perdeu pela culpa e recuperou pela graça, a fé e a compreensão das escrituras, pelas quais a mente humana é purificada, iluminada e aperfeiçoada para contemplar as coisas celestes, às quais o homem caído não pode chegar sem antes reconhecer seus próprios defeitos e trevas. Mas não pode fazer isto, se não considerar atentamente a ruína da natureza humana. (BOAVENTURA, 1983, p. 49).

Percebemos que Boaventura enaltece as explicações dadas por São Vitor e complementa, ao afirmar que o homem que chega ao último estágio consegue purificar sua alma e entender o que está além das coisas terrenas. Por meio de seu intelecto, compreende as coisas celestiais, totalmente abstratas e incompreensíveis para aqueles que não chegam a essa fase de contemplação.

Ainda apoiado no método de estudo de São Vítor, Boaventura explana sobre a tríplice fase de desenvolvimento da inteligência, afirmando que o homem só se torna semelhante a Deus por meio da inteligência. O homem sábio é o que consegue ser justo, entender e seguir as Sagradas Escrituras. Dessa maneira, ele se aproxima do Criador.

Pois o homem é semelhante a Deus quando é sábio e justo, ainda que o homem seja sábio e justo de maneira mutável, Deus de maneira imutável [...] Quando, portanto, nos dedicamos a reparar a nossa natureza (divina), esta é uma ação divina, mas quando providen- 
ciamos as coisas necessárias àquela parte de nós que é fraca, esta é uma ação humana. Toda ação, portanto, é ou divina ou humana. Podemos apropriadamente chamar aquela de 'inteligência', pelo fato de que se ocupa das coisas superiores, e esta de 'ciência', porque se ocupa das coisas inferiores e precisa de um certo qual conselho. Se, portanto, a Sapiência, como dissemos acima, guia todas as ações feitas pelo homem racional, é lógico dizermos que a Sapiência abrange duas partes, isto é 1) a inteligência e 2) a ciência. (HUGO DE SÃO VITOR, 2001, p. 67-69).

Para São Vitor, é a inteligência que, por meio da reflexão, leva o homem ao conhecimento da verdade. A ciência, por sua vez, é o que possibilita o desenvolvimento do intelecto, já que propicia ao homem a reflexão e o entendimento das coisas terrenas. Portanto, segundo São Vitor, a inteligência, ocupando-se das coisas superiores, fornece ao homem a compreensão do abstrato, ao passo que a ciência explica as coisas humanas.

0 autor pocura, mesmo que de forma não explícita, justificar a importância da fé e a necessidade do uso da razão. Ambas consituem a formação do homem, posto que, o esclarecimento da própria vida e da natureza não é justificado nem só por uma ou pela outra. Ele analisa que unidas, fé e razão, propiciam o que pode ser conhecido pela experiência e entendido como algo criado por um Ser Superior. Portanto, ele afere a inteligência dos que conseguem realizar esse entendimento com aqueles que só se importam com as minímas coisas, impondo-se a uma limitação de aprendizado.

Dessa forma, São Vitor, pela via do seu método de ensino, aborda a questão da leitura dos ensinamentos divinos, afirmando que ela instrui a mente do ser humano e o leva ao conhecimento do Criador. Esse conhecimento, para o autor, conduz à adoção de bons costumes e à imitação de bons comportamentos, o que aproxima o indivíduo do Ser Supremo. 0 seu método orienta como princípio da aprendizagem: a leitura, porém, não é qualquer leitura, é a leitura do Livro Sagrado, pelo qual, a interpretação faz com que o homem repense e reflita sobre as suas atitudes e ações.

Essa questão também é entendida por Boaventura como essencial para a humanidade. Para ele, se o homem se instrui e desenvolve a sabedoria, pode inter- pretar melhor as Palavras de Deus e fazer o bem. Logo, esse autor não pensa no individual, mas na sociedade. Sua preocupação é com o tratamento e os sentimentos que os indivíduos estão colocando em evidência, no contexto das transformações sociais que prevalecem no dia a dia em decorrência do desenvolvimento do comércio e das cidades.

O mérito da compreensão e do conhecimento do Livro Sagrado, segundo ele, depende da obediência aos ensinamentos divinos: se o homem sabe obedecer à mente, ciência interior que possibilita o entendimento das palavras sagradas, segue o bem e todos os sentimentos propostos por Deus para chegar à eternidade.

Porém, de acordo com Boaventura, esses bens são dados em vão e, por isso, é necessário que sejam deixados dois preceitos: um natural e outro disciplinar. 0 natural é aquele que cuida do bem dado e o disciplinar é o que, por via da obediência, faz o homem ser digno do bem prometido.

Ainda, preocupado com a queda do homem na direção de pecados mortais e com a possibilidade de ele não conseguir a eternidade, o Criador oferece quatro auxílios: dois por parte da natureza e dois por parte da graça.

O da ciência e o da consciência, auxílios que vêm da natureza do indivíduo, correspondem à mente, que tem sido dada por Deus para orientar sua conduta. Os denominados sindérese e graça originam-se da Graça Divina. À sindérese compete protestar contra as más ações, afirmar a razão da mente (o conhecer) sobre a razão prática (o agir). A graça, por sua vez, isto é, a graça divina, ilumina o intelecto com os sábios ensinamentos deixados por Deus: Assim, antes da queda, o homem teve perfeitos seis dons naturais, revestidos, além disso, pela graça divina. Daí infere-se claramente que, se caiu, foi só por sua culpa, por ter-se recusado a obedecer (BOAVENTURA, 1983, p. 64).

\section{CONCLUSÃO}

Compreender a relação entre fé e razão realizada pelo ensino da escolástica revela, por meio desses autores o compromisso com as questões divinas e a ne- 
cessidade do homem de conhecer o mundo, a natureza e ele próprio, inserido na sociedade dos séculos XII e XIII. Por exemplo, para Boaventura, o conhecimento está pautado em Deus: se existe razão, inteligência e a possibilidade de compreender o mundo é porque o Criador deu aos homens, juntamente com o intelecto, as condições de reflexão sobre a Sagrada Escritura. Seu principal argumento é o de que a via para se entender os ensinamentos divinos é a do intelecto e que a inteligência dada por Deus aos homens deve ser instruída pela Sagrada Escritura.

Entendemos que esses autores nos contemplam com exemplos de questões socioeducacionais, religiosas, morais, econômicas e políticas que nos favorecem a reflexão das alterações históricas ocorridas no ensino e que nos favoreceu a compreensão de que os ensinamentos realizados por São Vitor e São Boaventura contribuíram para algumas mudanças na educação dos homens nos séculos XII e XIII, pois mostraram à sociedade que o conhecimento, por meio da leitura, da filosofia, sobre os ensinamentos divinos, concede o aprendizado da reflexão, o qual possibilita o diálogo com Deus por meio das Escrituras.

Assim, o homem pode corresponder às vontades do Criador contidas na Palavra Sagrada, colocando em prática os sentimentos cristãos, disseminando amor, caridade e paz coletiva. Salientamos que o conhecimento ao qual os autores nos remetem é o de compreender a importância da formação humana por meio do conhecimento.

\section{REFERÊNCIAS}

BLOCH, Marc. Apologia da história: ou o ofício do historiador. Rio de Janeiro: Jorge Zahar, 2001.

BOAVENTURA de Bagnoregio. In: BONI, Luis A. de (Org.). Brevilóquio. Caxias do Sul: Livraria Sulina, 1963. Obras escolhidas.

BOAVENTURA de Bagnoregio. In: BONI, Luis A. de (Org.). Itinerário da Mente para Deus. Caxias do Sul: Livraria Sulina, 1963. Obras escolhidas.

BOAVENTURA de Bagnoregio. In: BONI, Luis A. de (Org.). Redução das ciências à Teologia. Caxias do Sul: Livraria Sulina, 1983. Obras escolhidas.

\section{BOAVENTURA de Bagnoregio. Escritos filosóficos-}

teológicos. Trad. de Luis A. De Boni. Porto Alegre: Edipucrs, 1999.

HUGO de São Vitor. Didascálicon da arte de ler. Tradução Antonio Marchioni. Petrópolis, RJ: Vozes, 2001.

MARCHIONI, Antonio. In: Hugo de São Vitor.

Didascálicon Da arte de ler. Petrópolis, RJ: Vozes, 2001. campus de Paranavaí; Doutora em Educação - vinculada ao Colegiado de Pedagogia e ao Programa de Mestrado em Ensino: Formação Docente Interdisciplinar - PPIFOR. Email: solperin01@gmail.com

\begin{abstract}
2 Professora titular da Universidade Estadual de Maringá - UEM; Doutora em Educação, Bolsa Produtividade/CNPq; Vinculada ao Departamento de Educação e ao Programa de Pós-Graduação em Educação-PPE. Email: teleoliv@gmail.com

3 Professor efetivo da Universidade Júlio Mesquita Filho - UNESP/campus de Assis/SP; Doutor em História; Vinculado ao Departamento de História e aos Programas de Pós-Graduação: em História da Unesp/Assis e do Mestrado em Ensino/PPIFOR - Unespar. Email: mendes.claudinei@gmail.com
\end{abstract}


